\section{Novel Coupling Reactions of Dithioacetals with Organocuprate Reagents. Propargylic Dithioacetal as an Allene-1,3-Zwitterion Synthon}

\author{
Hsian-Rong Tseng and Tien-Yau Luh*
}

Department of Chemistry, National Taiwan University, Taipe, Taiwan 106, Republic of China

\section{Received April 18, 1997}

The carbon-sulfur bond is known to be ambiphilic toward nucleophiles because the electronegativities for carbon and sulfur atoms are similar. Accordingly, different kinds of reagents or conditions may alter the selectivity of the reaction. It is well documented that the nickel-catal yzed cross-coupling reactions of organosulfur compounds with Grignard reagents provide a useful entry to convert a carbon-sulfur bond into a carbon-carbon bond. ${ }^{1,2}$ The carbon-sulfur bond in these reactions can be considered as a carbocation synthon. On the other hand, the production of a carbanionic leaving group from the corresponding thioether is rare unless a stabilized anionic species is produced. For example, the reaction of an ( $\alpha$-thioalkoxy)carbonyl compound with methyl mercaptide affords the corresponding desulfurized product. ${ }^{3}$ More recently, treatment of benzylic dithioacetals with organolithium reagents has led to the formation of the corresponding carbanions (eq 1). ${ }^{4}$

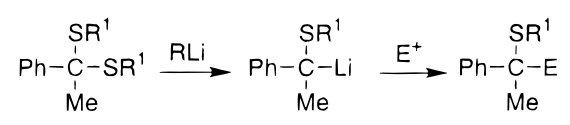

Whereas propargylic acetals react readily with organocopper reagents to give the corresponding ring-opening products, ${ }^{5}$ the corresponding reaction with sulfur analogs has not been explored. We recently reported that the propargylic dithioacetal $\mathbf{1}$ can serve as an allene-1,3dication synthon $\mathbf{2}$ upon treatment with the Grignard reagent in the presence of a nickel catalyst (eq 2). ${ }^{2,6}$ In this regard, the displacement of the two carbon-sulfur bonds by two carbon-carbon bonds can be achieved in one pot. However, the reaction would be more versatile if the two carbon-sulfur bonds in $\mathbf{1}$ could be substituted by different moieties. In this paper, we report an unprecedented organocopper-induced $\mathrm{C}-\mathrm{S}$ bond-cleavage reaction of propargylic dithioacetals leading to the corresponding thioethers $\mathbf{3}$ or $\mathbf{4}$. The combination of this process with the nickel-catalyzed cross coupling reaction

(1) For reviews, see: (a) Naso, F. Pure Appl. Chem. 1988, 60, 79. (b) Fiandanese, V. Pure Appl. Chem. 1990, 62, 1987. (c) Luh, T.-Y.; Ni, Z.-J. Synthesis 1990, 89.

(2) For reviews, see: (a) Luh, T.-Y. Acc. Chem. Res. 1991, 24, 257. (b) Luh, T.-Y.; Leung, M.-K. In Advances in the Use of Synthons in Organic Chemistry; Dondoni, A., Ed.; J Al: London, 1995; Vol. 2, 129. (c) Luh, T.-Y. Pure Appl. Chem. 1996, 68, 105.

(3) For example, see: Gassman, P. G.; Gilbert, D. P.; Luh, T.-Y. J . Org. Chem. 1977, 42, 1340.

(4) Krief, A.; Kenda, B.; Barbeaux, P. Tetrahedron Lett. 1991, 32, 2509.

(5) (a) Normant, J . F.; Alexakis, A. J . Organomet. Chem. 1973, 57, C99. (b) Alexakis, A.; Mangeney, P.; Normant, J . F. Tetrahedron Lett. 1985, 26, 4197. (c) Alexakis, A.; Mangeney, P.; Ghribi, A.; Marek, I.; Sedrani, R.; Normant, J . F. PureAppl. Chem. 1988, 60, 49. (d) Alexakis, A.; Mangeney, P. Tetrahedron: Asymmetry 1990, 1, 477. (e) Marek, I.; Mangeney, P.; Alexakis, A.; Normant, J . F . Tetrahedron Lett. 1986, 27, 5499. (f) Alexakis, A.; Marek, I.; Mangeney, P.; Normant, J . F. J . Am. Chem. Soc. 1990, 112, 8042.

(6) Tseng, H.-R.; Luh, T.-Y. J . Org. Chem. 1996, 61, 8685.
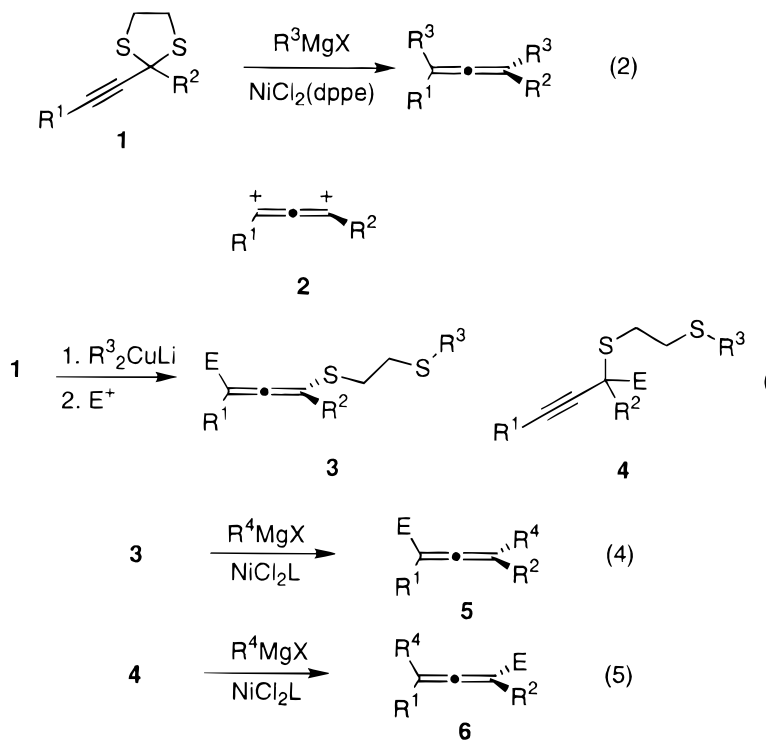

results in the sequential transformation of $\mathbf{1}$ into substituted allenes 5 or $\mathbf{6}$ (eqs $3-5$ ).

In the beginning of this work, we tested the reactivity of benzylic dithioacetals $\mathbf{7}$ toward organocopper reagents, Thus, each of $\mathbf{7 a}$ and $\mathbf{7 b}$ was treated with 0.6 equiv of ${ }^{\mathrm{t}} \mathrm{Bu}_{2} \mathrm{CuLi}$ at $-78{ }^{\circ} \mathrm{C}$ for $30 \mathrm{~min}$ followed by quenching with $\mathrm{MeOH}$ to give $\mathbf{8 a}$ and $\mathbf{8 b}$ in 95 and $90 \%$ yields, respectively (eq 6). These promising prel iminary results demonstrated the first examples of ring-opening reactions of dithiolanes with organocopper reagents.

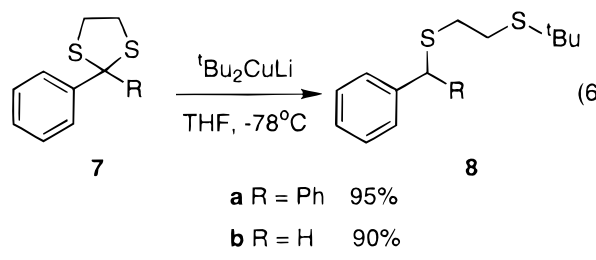

An extension of this procedure to the reaction of $\mathbf{l a}$ with the same copper reagent at $-78{ }^{\circ} \mathrm{C}$ followed by quenching with $\mathrm{MeOH}$ at $-78{ }^{\circ} \mathrm{C}$ gave the corresponding allenyl thioether $3 a$ in $88 \%$ yield. When $\mathrm{D}_{2} \mathrm{O}$ was employed to scavenge the reaction, deuterium incorporation at allenyl carbon $\left(C_{3}\right)$ was observed (Table 1 , entry 2). On the other hand, when 3 equiv of Mel and 2 equiv of $\mathrm{HMPA}^{7}$ were introduced at $-78^{\circ} \mathrm{C}$ instead of adding $\mathrm{D}_{2} \mathrm{O}$, methylation at the propargylic carbon occured to give 4a (Table 1, entry 7). Representative results are summarized in Table 1. Apparently, allenyl/propargyl organocopper intermediates $\mathbf{9}$ or $\mathbf{1 0}$ are involved in these reactions. It is noteworthy that neither $\mathbf{3}$ nor $\mathbf{4}$ reacted further with the organocopper reagent under these conditions.
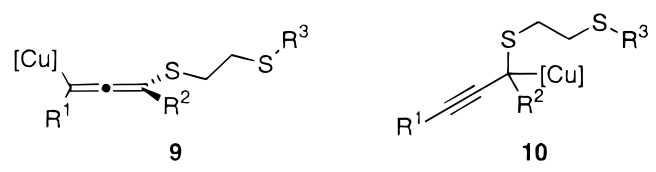

As can be seen from Table 1, a number of allenyl/ parpogylic thioethers $\mathbf{3 / 4}$ can be easily obtained from the reactions of $\mathbf{1}$ with organocopper reagents. Sequential

(7) HMPA was essential for the alkylation with Mel or allyl bromide under these conditions (Table 1 , entries 7 and 8). The yield was otherwise much lower. (Cf. Lipshutz, B. H. In Organometallics in Synthesis; Schlosser, M., Ed.; Wiley: Chichester, 1994; Chapter 4.) 
Table 1. Reaction of 1 with $R^{3}$ CuLi Followed by Treatment with Electrophile $\left(\mathrm{E}^{+}\right)$

\begin{tabular}{|c|c|c|c|c|c|c|}
\hline entry & substrate & $\mathrm{R}^{1}$ & $R^{2}$ & $R^{3}$ & $E$ & $\begin{array}{l}\text { product } \\
\text { (\% yield) }\end{array}$ \\
\hline 1 & la & $\mathrm{Ph}$ & $\mathrm{Me}$ & tBu & $\mathrm{H}$ & $3 a(88)$ \\
\hline 2 & & & & ${ }^{t} \mathrm{Bu}$ & D & 81) \\
\hline 3 & $\mathbf{l b}$ & $\mathrm{Ph}$ & $\mathrm{Ph}$ & tBu & $\mathrm{H}$ & $3 c(95)$ \\
\hline 4 & & & & ${ }^{\mathrm{n}} \mathrm{Bu}$ & $\mathrm{H}$ & 3d (93) \\
\hline 5 & 1c & $\mathrm{Bu}$ & $\mathrm{Me}$ & ${ }^{\mathrm{t}} \mathrm{Bu}$ & $\mathrm{H}$ & $3 e(82)$ \\
\hline 6 & 1d & TMS & $\mathrm{Me}$ & ${ }^{t} \mathrm{Bu}$ & $\mathrm{H}$ & 4c (94) \\
\hline 7 & la & $\mathrm{Ph}$ & $\mathrm{Me}$ & tBu & $\mathrm{Me}$ & $\mathbf{4 a}(81)$ \\
\hline 8 & & & & tBu & $\mathrm{CH}_{2}=\mathrm{CHCH}_{2}$ & $4 b(80)^{a}$ \\
\hline
\end{tabular}

a Crude yield. The product was used directly for the next reaction.

Table 2. $\mathrm{NiCl}_{2}$ (dppf)-Catalyzed Cross-Coupling

Reactions of 2 or $\mathbf{6}$ with Grignard Reagents

\begin{tabular}{cclc}
\hline entry & substrate & \multicolumn{1}{c}{$\mathrm{R}^{4} \mathrm{MgX}$} & $\begin{array}{c}\text { product } \\
\text { (\% yield) }\end{array}$ \\
\hline 9 & $\mathbf{3 a}$ & $\mathrm{MeMgl}$ & $\mathbf{5 a}(81)$ \\
10 & $\mathbf{3 e}$ & $\mathrm{PhMgBr}$ & $\mathbf{5 b}(67)$ \\
11 & $\mathbf{3 c}$ & $\mathrm{PrMgBr}^{\mathrm{P}}$ & $\mathbf{5 c}(50)$ \\
12 & $\mathbf{4 a}$ & $\mathrm{TMSCH} \mathrm{MgCl}^{\mathrm{M}}$ & $\mathbf{6 a}(72)$ \\
13 & $\mathbf{4 b}$ & $\mathrm{n} \mathrm{BuMgB}$ & $\mathbf{6 b}(62)$ \\
14 & $\mathbf{4 c}$ & $\mathrm{PhMgBr}$ & $\mathbf{6 c}(67)$ \\
15 & $\mathbf{3 a}$ & $\mathrm{MeMgl}$ & $\mathbf{1 1}(52)$
\end{tabular}

a $\mathrm{NiCl}_{2}$ (dppe) was employed as the catalyst.

treatment of these thioethers with the Grignard reagent in the presence of $5 \mathrm{~mol} \%$ of $\mathrm{NiCl}_{2}$ (dppf) resulted in a convenient synthesis of substituted allenes 5/6. Table 2 summarizes representative examples. As expected, 8 reduction of the $\mathrm{C}-\mathrm{S}$ bond in $3 \mathrm{c}$ was observed when ${ }^{\mathrm{i}}$. PrMgBr was employed (Table 2, entry 11).

When $\mathrm{NiCl}_{2}$ (dppe) was employed as the catalyst in the coupling reaction of $\mathbf{3 a}$, the corresponding dimeric prod- uct 11 was obtained in $52 \%$ yield (Table 2, entry 15). The stereochemistry of $\mathbf{1 1}$ was determined by the NOE experiments. Dimerization of $\mathbf{5 a}$ was also achieved in $59 \%$ yield upon treatment with $\mathrm{MeMgl}$ in the presence of $\mathrm{NiCl}_{2}$ (dppe).<smiles>C=C(C)C(=Cc1ccccc1)C(=Cc1ccccc1)C(C)C</smiles>

11

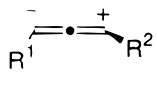

$12 a$<smiles>[R]C=[C+]</smiles>

$12 b$
In summary, we have demonstrated for the first time the use of propargylic dithioacetals as allene-1,3-zwitterion synthons 12. By employing this procedure, di-, tri-, as well as tetra-substituted allenes are thus synthesized conveniently.

Acknowledgment. This work was supported by the National Science Council of the Republic of China. We thank Professor Bruce H. Lipshutz for helpful discussions.

Supporting Information Available: NMR spectra for $\mathbf{3 a}-\mathbf{e}, \mathbf{4 a}, \mathbf{c}, \mathbf{5 b}$, and $\mathbf{6 a}-\mathbf{c}, \mathbf{8} \mathbf{a}, \mathbf{b}$, and 11 (14 pages).

J O970700V

(8) (a) Wenkert, E.; Hanna, J . M., J r.; Leftin, M. H.; Michel otti, E. L.; Potts, K. T.; Usifer, D. J . Org. Chem. 1985, 50, 1125. (b) Wenkert, E.: Ferreira, T. W. J . Chem. Soc., Chem. Commun. 1982 840. (c) Trost, B. M.; Lavoie A. C. J . Am. Chem. Soc. 1983, 105, 5075. (d) Trost, B. M.; Ornstein, P. L. J . Org. Chem. 1982 47, 748. (e) Shen, G.-Y.; Tapia, R.; Okamura, W. H.J . Am. Chem. Soc. 1987, 109, 7499. (f) Fabre, J -L.; J ulia, M. Tetrahedron Lett. 1983, 24, 4311. (g) Cuvigny, T.; Fabre, J.-L.; Hervé du Penhoat, C.; J ulia, M. Tetrahedron Lett. 1983, 24, 4319. (h) Fabre, J .-L.; J ulia, M.; Verpeaux, J .-L. Bull. Soc. Chim. Fr. 1985 772. (i) Capet, M, Cuvigny, T.; Hervé du Penhoat, C.; J ulia, M.; Loomis, G. Tetrahedron Lett. 1987, 28, 6273. 